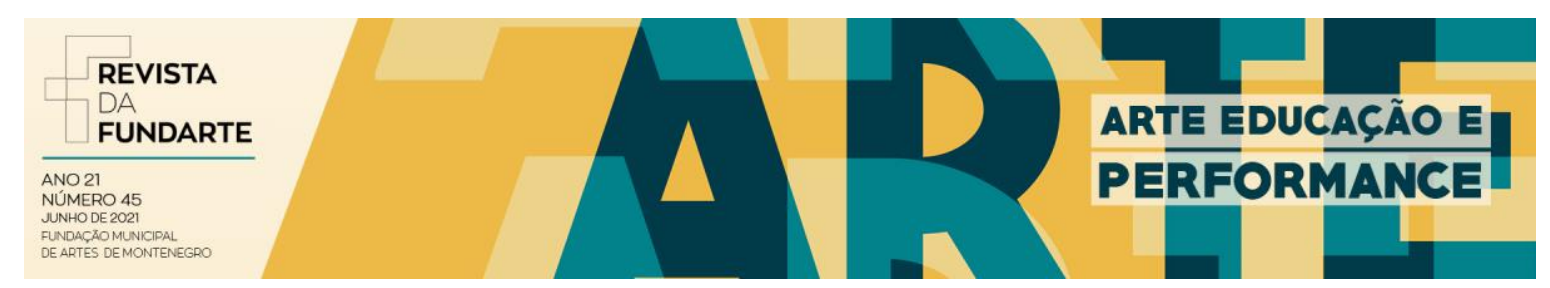

\title{
O CANTO ORFEÔNICO E SUA INFLUÊNCIA NA PRÁTICA DOCENTE
}

Eloilma Moura Siqueira Macedo

Filipe Ximenes Parente

DOI: $10.19179 / 2319-0868 / 815$

MACEDO, Eloilma Moura Siqueira; PARENTE, Filipe Ximenes Parente. O canto orfeônico e sua influência na prática docente. Revista da FUNDARTE. Montenegro, p.01-15, ano 21, no 45, junho de 2021.

Disponível em: http://.seer.fundarte.rs.gov.br/index.php/revistadafundarte/index> 30 de junho de 2021. 


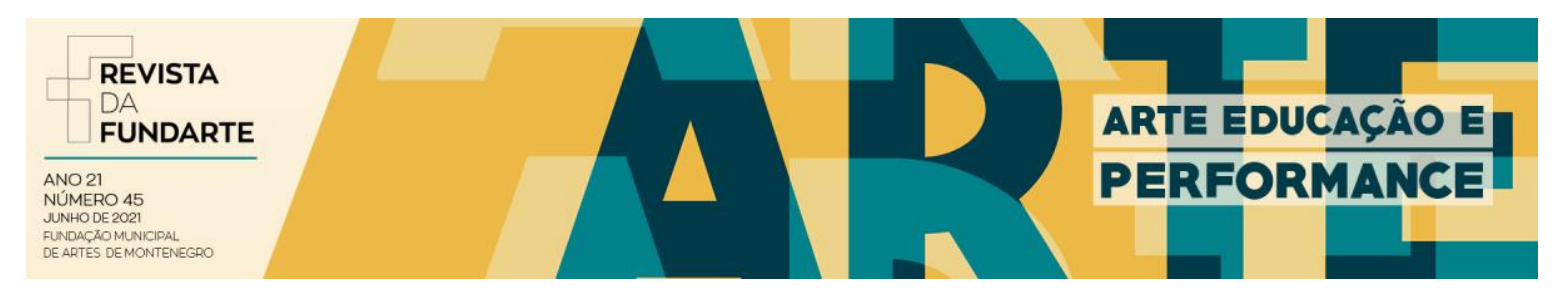

\title{
O CANTO ORFEÔNICO E SUA INFLUÊNCIA NA PRÁTICA DOCENTE
}

Eloilma Moura Siqueira Macedo 1 Filipe Ximenes Parente ${ }^{2}$

\begin{abstract}
Resumo: Esse artigo é resultado de reflexões elaboradas a partir de uma pesquisa de campo realizada em uma escola municipal localizada na cidade de Fortaleza, Ceará, e das análises feitas a partir da disciplina "Educação Musical Brasileira: Metodologias e Tendências", do curso de Licenciatura em Música da Universidade Federal do Ceará. Tem como objetivo destacar a influência que o Canto Orfeônico, implantado por Heitor Villa-Lobos no Brasil, exerce até os dias atuais no ensino de Música na escola básica. Tal constatação se deu após uma visita in loco e à entrevista aberta realizada com o professor de Arte atuante nele, sendo também uma pesquisa de cunho metodológico qualitativo (MINAYO, 2009). O aporte teórico dispõe dos estudos de Freire (2018), Lisboa (2015), Loureiro (2001) e Souza (2012).
\end{abstract}

Palavras-chave: Educação Musical; Canto Orfeônico; Prática Docente.

\section{THE ORPHEONIC SINGING AND ITS INFLUENCE ON TEACHING PRACTICE}

\begin{abstract}
This article is the result of reflections elaborated from a field research carried out in a municipal school located in the city of Fortaleza, Ceará, and from the analyzes made from the discipline "Brazilian Music Education: Methodologies and Trends", from the course of Degree in Music from the Federal University of Ceará. Its purpose is to highlight the influence that Canto Orfeônico, implemented by Heitor Villa-Lobos in Brazil, exerts until today in the teaching of Music in elementary school. This finding took place after an on-site visit and an open interview conducted with the art
\end{abstract}

\begin{abstract}
1Estudante do curso de Música-Licenciatura da Universidade Federal do Ceará, formada em Artes Visuais (2014) pelo Instituto Federal de Educação, Ciência e Tecnologia (IFCE), mestranda em Artes pelo PPGARTES-IFCE e professora efetiva de Arte da rede municipal de ensino de Fortaleza-Ce.

2 Possui graduação em Pedagogia pela Universidade Estadual Vale do Acaraú (2009). Graduação em Arte Educação pela Faculdade Integrada da Grande Fortaleza (2014). Pós graduação em nível de especialização em Música pela Faculdade Vale do Jaguaribe (2011); pós graduação em nível de especialização em Psicopedagogia pela Faculdade Christus (2012), Mestrado em Educação pela Universidade Federal do Ceará (2015), Doutorado em Educação da Universidade Federal do Ceará (2018). Além de formações complementares em educação musical e pedagogia. Tem formação em clarinete pelo festival Eleazar de Carvalho (2005; 2012; 2015); e formação em Regência Orquestral pelo mesmo Festival $(2017 ; 2018)$. Foi professor de artes e música em escolas públicas e particulares. Foi professor do ensino superior atuando na área de artes, música e pedagogia. Foi regente de grupos de flauta, corais infantis e grupo de violões. Tem experiência na área da Educação, no ensino e aprendizagem de música e na formação continuada para professores. Foi coordenador e maestro da Orquestra Sinfônica da UFC. Atuou como coordenador do Programa Institucional de Bolsas de Iniciação a Docência (PIBID) e Residência Pedagógica/Música. Foi tutor do curso de Pedagogia da UAB Virtual (2015) e professor formador do PARFOR (2019). Atualmente é professor do Curso de Licenciatura em Música da UFC, coordenador e maestro da Banda Sinfônica da UFC, coordenador do grupo de pesquisa: Ensino e Aprendizagem para grupos musicais vinculado ao CNPq, e professor do Mestrado do Instituto Federal do Ceará (IFCE).
\end{abstract}

MACEDO, Eloilma Moura Siqueira; PARENTE, Filipe Ximenes Parente. O canto orfeônico e sua influência na prática docente. Revista da FUNDARTE. Montenegro, p.01-15, ano 21, ํㅡ 45, junho de 2021.

Disponível em: http://.seer.fundarte.rs.gov.br/index.php/revistadafundarte/index> 30 de junho de 2021. 


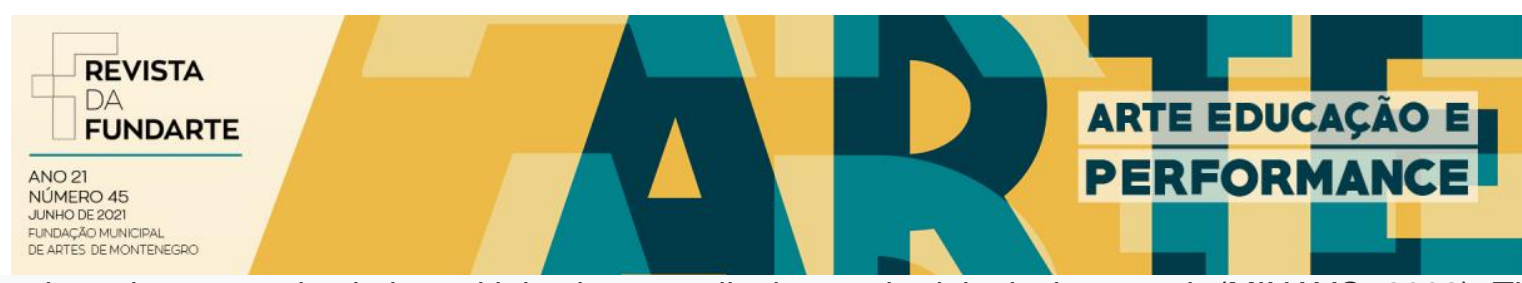

teacher who was active in it, and it is also a qualitative methodological research (MINAYO, 2009). The theoretical contribution includes studies by Freire (2018), Lisbon (2015), Loureiro (2001) and Souza (2012).

Keywords: Music Education; Orpheonic Corner; Teaching Practice.

\section{INTRODUÇÃO}

O presente artigo é resultado das reflexões construídas a partir dos temas discutidos na disciplina intitulada Educação Musical Brasileira: Metodologias e Tendências do curso de Música - Licenciatura da Universidade Federal do Ceará (UFC). Tem como finalidade destacar a influência que o Canto Orfeônico, implantado por Heitor Villa-Lobos no Brasil, exerce até os dias atuais no ensino de música em uma determinada escola pública de Fortaleza-Ce.

A curiosidade de pesquisa veio após uma visita ${ }^{3}$ a uma escola pública municipal de ensino fundamental II de Fortaleza para conhecer o professor e seu contexto de trabalho e, veio também, de umas das demandas da disciplina. Nela éramos levados a conhecer e refletir sobre diversas metodologias de ensino de Música, bem como seus autores, e a compreender qual seria o tipo de Música que levaríamos para nossos futuros alunos na escola, refletindo sobre abordagens, estilos musicais e musicalidades. As metodologias demonstradas em aula foram as de Dalcroze (1906), Koellreutter (1986), Sá Pereira (1964), Elvira Drummond (1998), Gramani (1996), Lucas Ciavatta (2012) e Villa-Lobos (1937), e uma das atividades da disciplina era visitar um contexto escolar público, entrevistar um professor de Música e, se possível, ligar a prática docente do mesmo a algum dos métodos vistos em aula, refletindo sobre como as metodologias estudadas podem influenciar a prática docente na atualidade.

Visitamos um professor licenciado em Música pela UFC e realizamos uma entrevista aberta, que consiste em perguntas feitas pelo investigador que buscam dar maior profundidade às reflexões, dando maior liberdade para o entrevistado falar

\footnotetext{
${ }^{3} \mathrm{~A}$ visita foi feita em trio e fez parte das atividades propostas pela disciplina para conscientização e integração dos alunos com o ambiente escolar e para socialização do apreendido com os demais colegas da turma.
}

MACEDO, Eloilma Moura Siqueira; PARENTE, Filipe Ximenes Parente. O canto orfeônico e sua influência na prática docente. Revista da FUNDARTE. Montenegro, p.01-15, ano 21, no 45, junho de 2021.

Disponível em: http://.seer.fundarte.rs.gov.br/index.php/revistadafundarte/index> 30 de junho de 2021. 


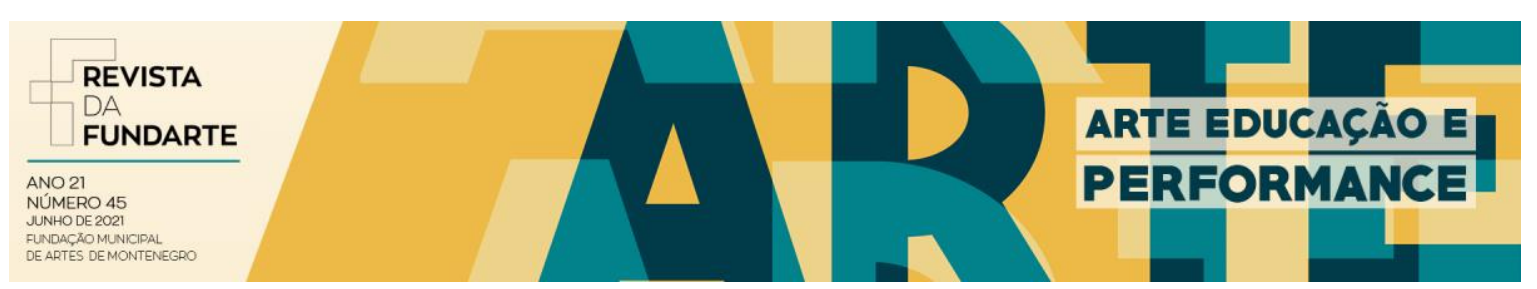

livremente sobre um tema (MINAYO, 2009). As perguntas guias eram focadas na estrutura física escolar e na metodologia de ensino, sendo elas abertas para que o professor pudesse ficar à vontade em suas respostas. As discussões a respeito de tais respostas serão feitas em tópicos mais adiante.

Após compreender as metodologias de ensino musical feitas em sala de aula e de fazer a visita ao contexto escolar, passamos a fazer correlações com a temática de Villa-Lobos, o Canto Orfeônico, e a prática pedagógica do professor entrevistado. Dessa forma, o objetivo principal desta pesquisa é destacar a influência do Canto Orfeônico no ensino de música em uma determinada escola pública na atualidade, sendo os objetivos específicos: conceituar o Canto Orfeônico; contextualizar prática do Canto Orfeônico no campo histórico e social; descrever a visita feita à escola e ao professor; e relacionar a prática pedagógica do professor às primícias do Canto Orfeônico.

Esta pesquisa tem como caráter metodológico a abordagem qualitativa, pois está centrada na compreensão e explicação de aspectos que não podem ser quantificados. Segundo Minayo (2009):

Ela trabalha com o universo dos significados, dos motivos, das aspirações, das crenças, dos valores e das atitudes. (...) O universo da produção humana que pode ser resumido no mundo das relações, das representações e da intencionalidade e é objeto da pesquisa qualitativa dificilmente pode ser traduzido em números e indicadores quantitativos. (MINAYO, 2009. p. 21).

É também uma pesquisa de campo, pois recorreu à coleta de dados junto à pessoas e em um local específico (GERHARDT e SILVEIRA, 2009). A coleta de dados se deu por meio de entrevista aberta, onde perguntas foram elaboradas previamente, porém a análise não estava presa somente a estas questões, pois as mesmas permitiam flexibilidade ao diálogo.

Nos tópicos seguintes apresentamos um breve histórico e conceituação do Canto Orfeônico, descrição da visita realizada na escola pública de Fortaleza-Ce em

MACEDO, Eloilma Moura Siqueira; PARENTE, Filipe Ximenes Parente. O canto orfeônico e sua influência na prática docente. Revista da FUNDARTE. Montenegro, p.01-15, ano 21, no 45, junho de 2021.

Disponível em: http://.seer.fundarte.rs.gov.br/index.php/revistadafundarte/index> 30 de junho de 2021. 


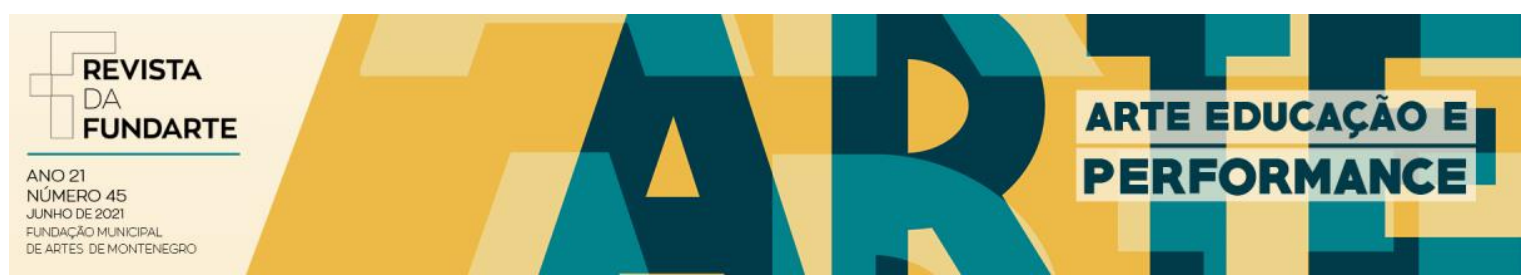

questão e a relação da prática pedagógica do professor entrevistado com algumas das bases do Canto Orfeônico.

\section{BREVE HISTÓRICO DO CANTO ORFEÔNICO}

No final de 1920 surgiu uma corrente artística chamada de Movimento Nacionalista, na qual os compositores buscavam expressar uma cultura musical característica de sua nação, elevando o sentimento patriótico por meio de hinos nacionais, canções folclóricas, marchas e musicalização da literatura local (LISBOA, 2005).

Os governos, em diversas nações, também tomados por este nacionalismo, estavam no poder e, no Brasil, Getúlio Vargas assume após a Revolução de 1930 que destituiu Washington Luís e impediu a posse de Júlio Prestes. Nesse período, Vargas centralizou o poder em sua figura e se aproximou das massas, característica marcante do período chamado de Estado Novo. Ele permaneceu no poder até 1945, quando foi forçado a renunciar à presidência por causa de um ultimato dos militares (LISBOA, 2005).

Nesse período Heitor Villa-Lobos tornou-se aliado de Getúlio Vargas e iniciou o movimento intitulado Canto Orfeônico, mesclando ideais artísticos e políticos.

O Canto Orfeônico é uma pedagogia musical voltada para as escolas primárias e foi desenvolvida no contexto de valorização nacional, em vários países como a França, a Alemanha e a Espanha no século XIX. No Brasil e em alguns países da América Latina tal pedagogia foi adaptada e se desenvolveu na primeira metade do século $X X$.

[...] tinha como objetivo promover a teatralização e a ritualização de vários símbolos nacionais, que estavam na época sendo construídos por meio de projetos pedagógico-sociais, com o intuito de criar uma comunidade sensível aos ideais patrióticos e à política nacionalista, em voga tanto na Europa do século XIX quanto no Brasil nos anos 1930. (SOUZA, 2012, p. $68)$.

Oficialmente o Canto Orfeônico foi idealizado por Villa-Lobos durante os anos de 1930. O músico fez desta pedagogia uma de suas principais bandeiras e teve

MACEDO, Eloilma Moura Siqueira; PARENTE, Filipe Ximenes Parente. O canto orfeônico e sua influência na prática docente. Revista da FUNDARTE. Montenegro, p.01-15, ano 21, no 45, junho de 2021.

Disponível em: http://.seer.fundarte.rs.gov.br/index.php/revistadafundarte/index> 30 de junho de 2021. 


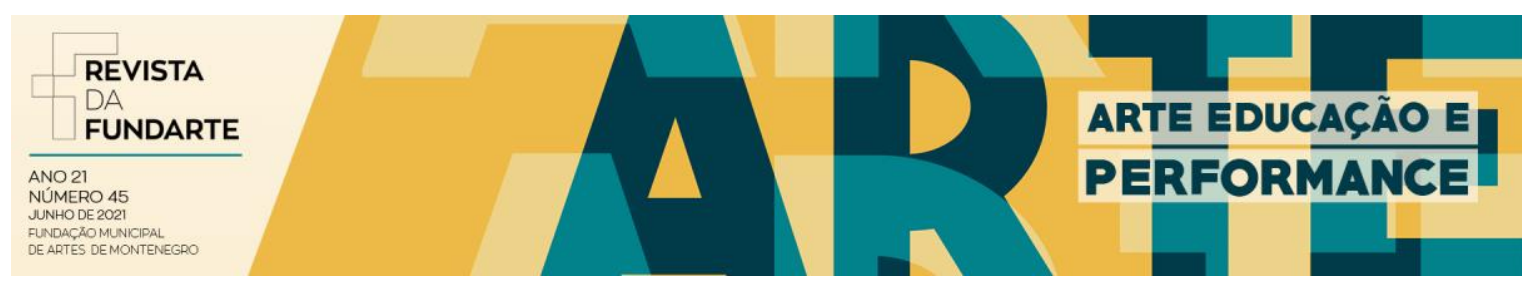

posição ativa como diretor da Superintendência da Educação Musical e Artística (SEMA), na coordenação pedagógica, na formação de professores, na escrita de material pedagógico e na propaganda da prática musical, sendo também 0 responsável por adaptar o Canto Orfeônico para o contexto nacional (SOUZA, 2012).

O movimento inseriu o Canto Orfeônico como disciplina obrigatória nos currículos das escolas públicas de ensino secundário, a partir do Decreto Federal oㅜ 19.890 de 18 de abril de 1931. Tal decreto "fez parte de uma reforma do ensino público que ficou conhecida como "Reforma Francisco Campos" (LISBOA, 2005, p. 22).

A Reforma Francisco Campos, juntamente com a criação do Conselho Nacional de Educação, fez parte de esforços para impor em todos os níveis de educação uma estrutura comum em todo território nacional, excluindo o ensino primário elementar, que corresponde hoje ao ensino fundamental I. A disciplina Música (Canto Orfeônico) estava destinada aos três primeiros anos do curso fundamental, que hoje corresponde ao ensino fundamental II.

De acordo com Cruvinel (2005), o movimento do Canto Orfeônico no Brasil, na década de 1930, foi uma das primeiras iniciativas de sistematização do ensino coletivo musical. Tinha como objetivo a melhoria do nível de Educação Musical de base, auxiliar o desenvolvimento artístico da criança, produzir adultos musicalmente alfabetizados e formar um sentimento cívico de amor à pátria, por meio de canções folclóricas e hinos pátrios, de acordo com o pensamento do Estado Novo. Houve também capacitação de professores para maior difusão do Canto Orfeônico.

Para Villa-Lobos, a voz cantada era o melhor instrumento para a democratização e acesso ao ensino de Música, pois é um instrumento acessível a todos e, por isso, a prática do Canto Orfeônico nas escolas impõe-se como uma solução lógica. Durante este período foi criada por Getúlio Vargas a Superintendência da Educação Musical e Artística (SEMA), que implantou o Canto Orfeônico nas escolas. Órgãos semelhantes a SEMA foram criados no Rio Grande do Sul, São Paulo, Bahia, Sergipe, Paraíba, Piauí, Ceará, Amazonas, Rio Grande do influência na prática docente. Revista da FUNDARTE. Montenegro, p.01-15, ano 21, no 45, junho de 2021.

Disponível em: http://.seer.fundarte.rs.gov.br/index.php/revistadafundarte/index> 30 de junho de 2021. 


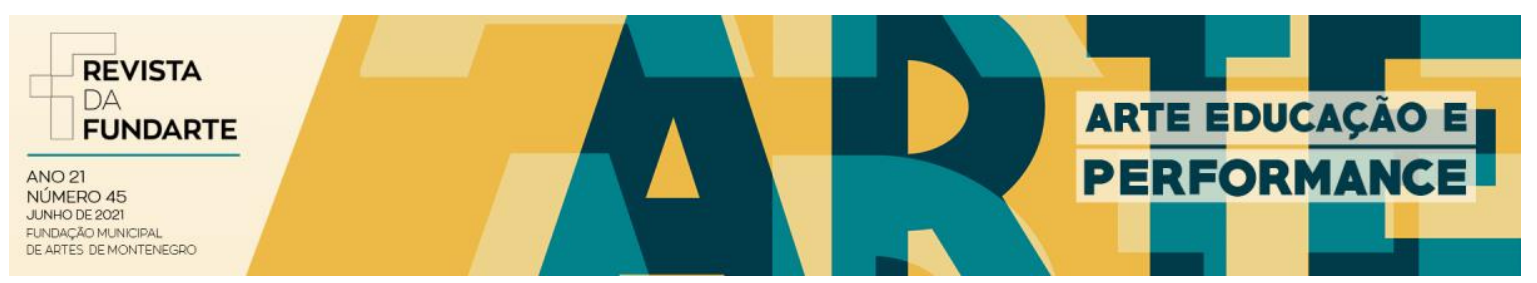

Norte e Minas Gerais, com o objetivo de difundir o ensino de música como veículo de propagação do civismo. Dessa forma, a sistematização nacional de uma pedagogia musical contribuiu para a valorização do ensino de música no país.

A SEMA foi criada em 1932 e dirigida desde seu início por Villa-Lobos a convite de Anísio Teixeira, secretário de Educação do Distrito Federal, na época, situado no Rio de Janeiro. O secretário corroborava com as ideias de John Dewey (1959), que deram base para o movimento da Escola Nova 4 .

Segundo Lisboa (2005), Villa-Lobos compreendia a música como base e agente imprescindível à educação do caráter da juventude, sendo a implantação dela como disciplina na escola pública um meio de acesso à música para todas as classes sociais. Villa-Lobos aponta os benefícios do Canto Orfeônico:

\begin{abstract}
Em primeiro lugar, reúne todos os elementos essenciais à verdadeira formação musical: - a iniciação segura do ritmo, a educação auditiva, a sensação perfeita dos acordes. E, mais tarde, o tirocínio da leitura, a compreensão e a familiaridade com as ideias melódicas e com os textos expressos pelos autores diversos e, por último, as sensações de ordem propriamente estética: - faculdade de emoção ante a beleza melódica ou ante a capacidade dinamogênica do ritmo. Em segundo lugar, o canto coletivo, com o seu poder de socialização, predispõe o indivíduo a perder no momento necessário a noção egoísta da individualidade excessiva, integrando-o na comunidade, valorizando no seu espírito a ideia da necessidade da renúncia ante os imperativos da coletividade social, favorecendo, em suma, essa noção de solidariedade humana, que requer da criatura uma participação anônima na construção das grandes nacionalidades [...] Entretanto, o seu mais importante aspecto educativo é, evidentemente, o auxílio que o canto coletivo veio prestar à formação moral e cívica da infância brasileira. (VILLA-LOBOS, s.d., p. 9-10 apud LISBOA, 2005, p. 27).
\end{abstract}

A formação cívica dos alunos se dava pelo uso de um repertório musical baseado na pesquisa, arranjo, estudo e execução de música nacional e folclórica. Essa última, seria a mais facilmente assimilada por crianças, pois já fazia parte do seu repertório.

\footnotetext{
${ }^{4}$ A Escola Nova tem como base a crença de que a educação é o exclusivo elemento verdadeiramente eficaz para a construção de uma sociedade democrática, que leva em consideração as diversidades, respeitando a individualidade do sujeito, aptos a refletir sobre a sociedade e capaz de inserir-se nessa sociedade Então de acordo com alguns educadores, a educação escolarizada deveria ser sustentada no indivíduo integrado à democracia, o cidadão atuante e democrático.
}

MACEDO, Eloilma Moura Siqueira; PARENTE, Filipe Ximenes Parente. O canto orfeônico e sua influência na prática docente. Revista da FUNDARTE. Montenegro, p.01-15, ano 21, no 45, junho de 2021.

Disponível em: http://.seer.fundarte.rs.gov.br/index.php/revistadafundarte/index> 30 de junho de 2021. 


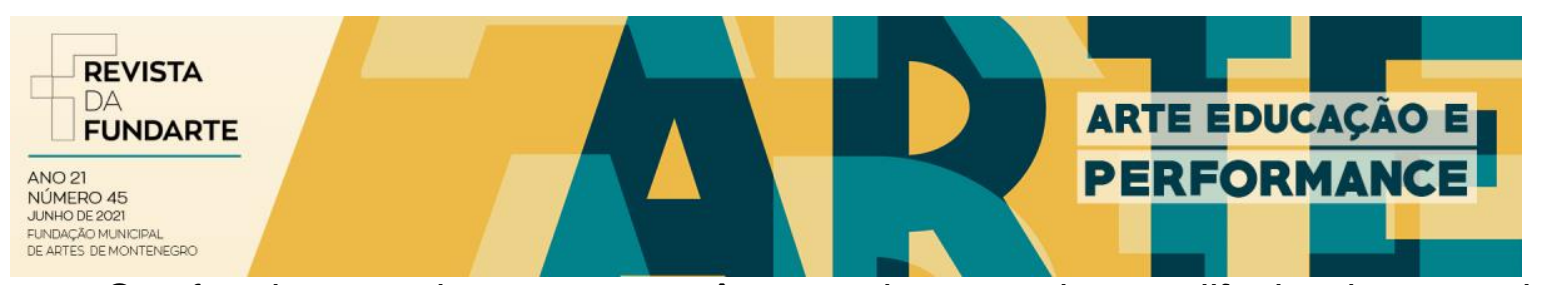

O orfeonismo se baseava em três conceitos, a saber: califasia - busca pela pronúncia perfeita do texto cantado; califonia - busca do canto perfeito em melodia e afinação; calirritmia - busca pela sincronia perfeita entre a palavra cantada e o ritmo da música (LISBOA, 2005).

De acordo com Lisboa (2005) a implantação do Canto Orfeônico como disciplina nas escolas públicas:

Solucionaria o problema da educação musical como monopólio de elite ao incluí-la num modelo de ensino popular; faria com que a música nacional tomasse conhecimento de si mesma "pela apreensão total do conjunto de fenômenos históricos sociais e psicológicos, capazes de determinar os seus caracteres étnicos, as suas tendências naturais e o seu ambiente próprio" (VILLA-LOBOS, 1946, p. 500); formaria, assim, uma consciência musical brasileira entre a infância e juventude que reformaria aos poucos a mentalidade das gerações futuras (ib, p. 500); e aproveitaria a música como elemento educativo de formação moral e cívica. Na conquista de todos esses objetivos, a música então encontraria seu papel dentro da ideologia nacionalista, unindo e integrando a ideia de povo e de raça brasileira às suas raízes, por meio do canto orfeônico. (LISBOA, 2005, p. 30).

Assim, apoiado pelos poderes federais e municipais, Villa-Lobos inicia a implantação do Canto Orfeônico, começando pelo Distrito Federal e se expandindo para as demais regiões do Brasil. O movimento de inserção dessa prática musical ficou enfraquecido após a morte de Villa-Lobos em 1959 e teve uma pausa histórica em 1961 com a promulgação da Lei de Diretrizes e Bases da Educação Nacional (LDB 4.024/1961), que substituiu o Canto Orfeônico pelo ensino optativo de Música.

Destarte observamos que o Canto Orfeônico passou por tais etapas, sendo um fator importante na democratização do ensino de música na escola básica e na difusão da cultura e folclore brasileiros.

No tópico seguinte será descrita a visita ao contexto escolar, que teve o objetivo de conhecer o professor e seu contexto de trabalho. Tal descrição foi divida em Estrutura Física, Quadro Funcional e Metodologia de Ensino do Professor.

MACEDO, Eloilma Moura Siqueira; PARENTE, Filipe Ximenes Parente. O canto orfeônico e sua influência na prática docente. Revista da FUNDARTE. Montenegro, p.01-15, ano 21, no 45, junho de 2021.

Disponível em: http://.seer.fundarte.rs.gov.br/index.php/revistadafundarte/index> 30 de junho de 2021. 


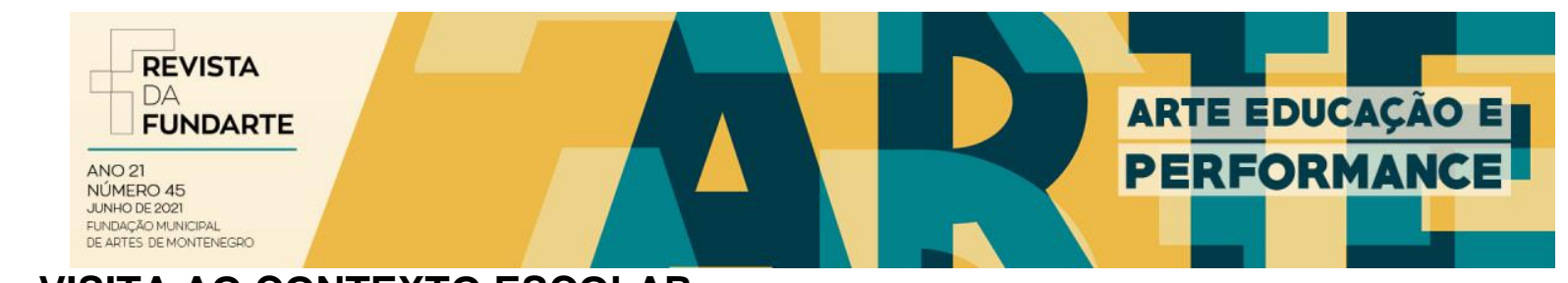

\section{VISITA AO CONTEXTO ESCOLAR}

Visitamos uma escola pública ${ }^{5}$ de ensino municipal em Fortaleza-Ce e conversamos com o professor de área específica $A_{r t e}{ }^{6}$, formado em Música. 0 encontro foi durante o horário de planejamento do mesmo e realizamos a entrevista no refeitório da escola.

O relatório da visita foi dividido em categorias para melhor compreensão de seu conteúdo. Discorreremos em tópicos sobre Estrutura Física, Quadro Funcional e Metodologia de Ensino do Professor.

\section{Estrutura Física}

A escola possui 13 salas de aula, uma sala de professores, laboratório de informática, diretoria, quadra de esportes coberta, parque infantil, banheiro padrão e para deficientes físicos, refeitório, cozinha, pátio coberto, sala de recursos multifuncionais para Atendimento Educacional Especializado (AEE), biblioteca, secretaria e despensa.

Para as aulas de Arte, a escola disponibiliza um violão, conjunto de percussão para fanfarra e um teclado. A escola não dispõe de uma sala específica para as práticas artísticas. $O$ professor também relatou que adquiriu seu próprio equipamento multimídia, como aparelho de datashow, caixa de som e computador, para utilizar como suporte em suas aulas teóricas.

\section{Quadro Funcional}

Trabalham na instituição de ensino 79 funcionários para atender cerca de 780 alunos, segundo o censo escolar de 20187 , distribuídos entre Ensino Fundamental I, Ensino Fundamental Il e Educação de Jovens e Adultos (EJA).

\footnotetext{
${ }^{5}$ Não houve pedido de autorização para uso do nome da escola e do professor neste artigo, portanto os mesmos serão preservados.

${ }^{6}$ Esta é a nomenclatura utilizada pela prefeitura municipal de Fortaleza para definir o cargo dos professores formados em Música, Artes Visuais, Teatro ou Dança que dão aula da disciplina, também intitulada por eles, de Artes/Literatura.

${ }^{7}$ Fonte: https://www.melhorescola.com.br/escola/publica/
}

MACEDO, Eloilma Moura Siqueira; PARENTE, Filipe Ximenes Parente. O canto orfeônico e sua influência na prática docente. Revista da FUNDARTE. Montenegro, p.01-15, ano 21, no 45, junho de 2021.

Disponível em: http://.seer.fundarte.rs.gov.br/index.php/revistadafundarte/index> 30 de junho de 2021. 


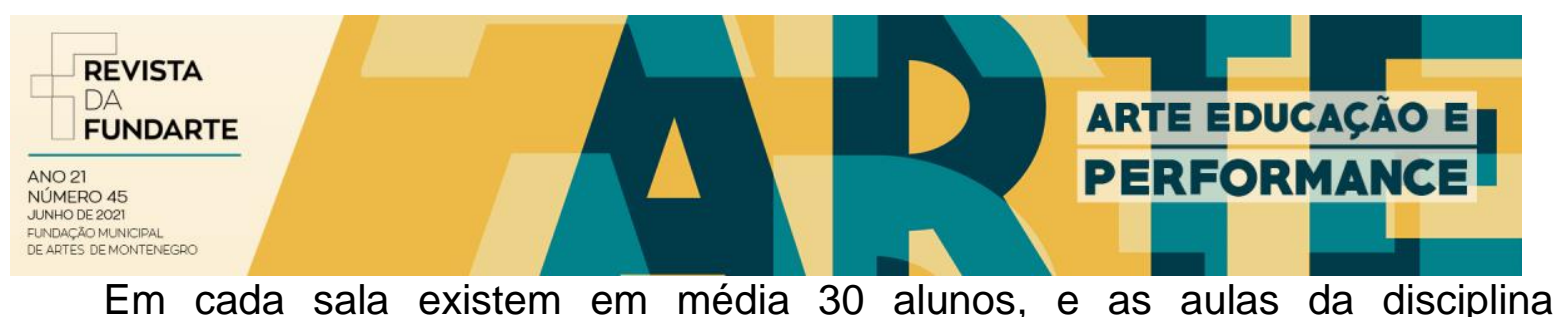

Artes/Literatura, duram 55 minutos por semana no ensino fundamental II.

\section{Metodologia de Ensino do Professor}

O material didático adotado pela escola é o livro "Por Toda Parte" da editora FTD, porém o professor relatou que não é obrigado a segui-lo nem utilizá-lo em todas as aulas, sendo livre para abordar o conteúdo que desejar.

Em relação à duração das aulas, o professor relatou que tem uma hora/aula em cada uma de suas turmas, atestando que este tempo é escasso para aula. Afirmou também que, no começo, foi difícil, pois não sabia lidar com conflitos da profissão docente e da convivência com os alunos e colegas, mas depois de frequentar terapia, ele compreendeu que seu papel na escola era o de mostrar a Arte em geral para os alunos, focando numa formação estética vinculada às vivências artísticas e à teoria.

Questionado sobre como se dava sua aula prática, o professor relatou que, por não ter sala adequada e falta de instrumentos para todos os alunos, prefere utilizar o canto como ferramenta de musicalização. Relatou também que ele não é obrigado a escolher uma linguagem da Arte em detrimento das outras, mas opta pelo ensino de Música, por ser esta a sua formação.

Ainda sobre o canto, o professor relatou que a voz é um instrumento acessível a todos, desde que não possuam deficiências relacionadas à voz e à audição, e isto faz dela um instrumento potente de democratização do ensino de música. Dessa forma, observamos um elo entre o discurso do professor e a metodologia de Heitor Villa-Lobos (LISBOA, 2005). Afirmou também que escolhe músicas do repertório dos alunos ou músicas nacionais que tem forte apelo popular, faz arranjos a duas vozes e aplica com os alunos em algumas de suas aulas práticas. Esta prática do professor coaduna com a escuta e valorização dos contextos e conhecimentos prévios dos educandos abordada por Freire (2018). O autor afirma que devemos escutar os alunos, não apenas no sentido auditivo, mas permanecer sempre disponíveis para escutar e dar abertura à fala do outro, seus

MACEDO, Eloilma Moura Siqueira; PARENTE, Filipe Ximenes Parente. O canto orfeônico e sua influência na prática docente. Revista da FUNDARTE. Montenegro, p.01-15, ano 21, no 45, junho de 2021.

Disponível em: http://.seer.fundarte.rs.gov.br/index.php/revistadafundarte/index> 30 de junho de 2021. 


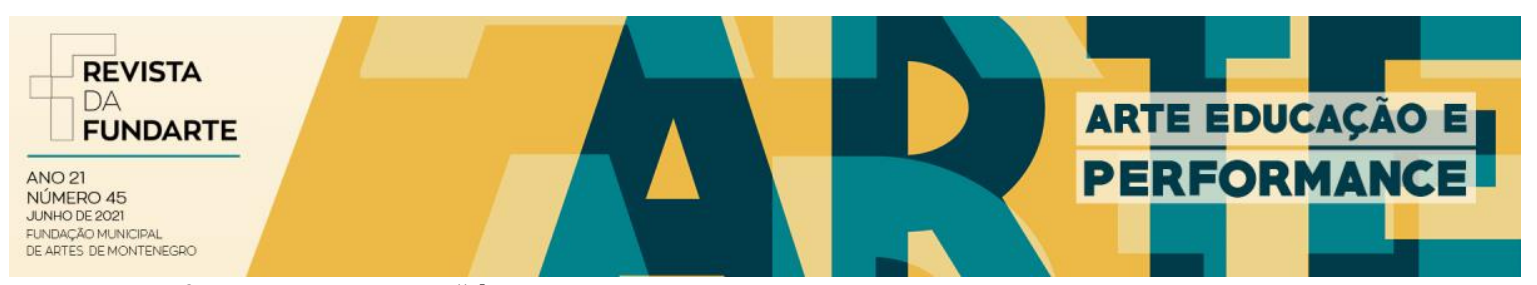

gestos e diferenças, pois "é escutando bem que me preparo para melhor me colocar ou melhor me situar do ponto de vista das ideias" (FREIRE, 2018, p. 117).

Isto posto, podemos observar e refletir sobre a prática do docente entrevistado e fazer inter-relações com a metodologia orfeônica, percebendo semelhanças e divergências. A seguir detalharemos algumas práticas e faremos as correlações entre tal práxis pedagógica e o Canto Orfeônico com o objetivo de destacar a influência que esta metodologia, implantada por Heitor Villa-Lobos no Brasil, é exercida até os dias atuais no ensino de Música na escola básica.

\section{RELAÇÃO ENTRE A PRÁTICA PEDAGÓGICA E O CANTO ORFEÔNICO}

$\mathrm{Na}$ fala do professor entrevistado é notório o uso da voz como instrumento facilitador da Educação Musical, pois são poucos os instrumentos e materiais disponíveis, sendo a voz um instrumento natural comum a todos que não possuem deficiências relacionadas a ela. O professor utiliza a voz para fomentar suas aulas práticas.

O docente relatou que escolhe as músicas do repertório dos alunos e as que têm forte apelo popular, como as que tocam nas rádios ou tem muitas visualizações em sites de exibição de videoclipes. Tais características podem ser comparadas ao Canto Orfeônico quanto à utilização da voz como instrumento musical e quanto ao uso de músicas que fazem parte da cultura local. Sabemos que as músicas tocadas nas rádios ou em sites específicos não são folclóricas, porém podemos notar que a partir delas o professor trabalha aspectos como ritmo, afinação, percepção, leitura musical e o canto coletivo, sendo estes aspectos também trabalhados no Canto Orfeônico.

Porém, existem divergências. No Canto Orfeônico existia um conteúdo comum a ser seguido por todas as escolas, já na prática docente do professor entrevistado, ele está livre para escolher o conteúdo que julgar melhor para lecionar, sendo do livro didático adotado ou não. Os livros de Arte adotados pelas escolas municipais de Fortaleza nem sempre são iguais. De quatro em quatro anos são oferecidas diversas opções de livros para os professores que escolhem aquele que

MACEDO, Eloilma Moura Siqueira; PARENTE, Filipe Ximenes Parente. O canto orfeônico e sua influência na prática docente. Revista da FUNDARTE. Montenegro, p.01-15, ano 21, no 45, junho de 2021.

Disponível em: http://.seer.fundarte.rs.gov.br/index.php/revistadafundarte/index> 30 de junho de 2021. 


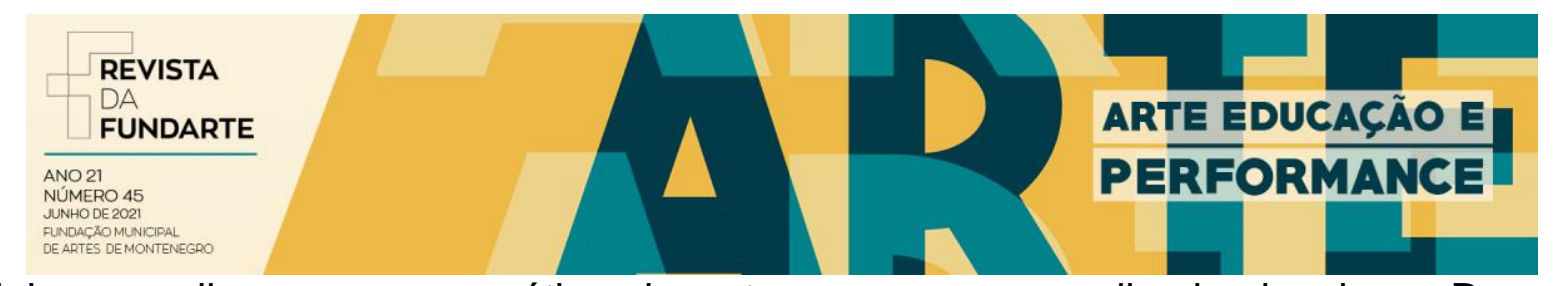

julgam melhor para sua prática docente e para o aprendizado do aluno. Dessa forma, há divergências entre os conteúdos ensinados nas escolas.

O professor, também, não expressou preocupação em preservar a cultura brasileira ou louvar os símbolos nacionais, porém afirmou que escolhia apenas músicas de brasileiros, mas não deu justificativa para tal escolha. Podemos conjecturar que seja pela dificuldade que alunos podem vir a ter ao cantar em outras línguas.

Segundo Loureiro (2001), o projeto de Villa-Lobos tinha o desejo de educar as massas urbanas por meio da música. Na prática docente do entrevistado, o desejo é a formação estética por intermédio das vivências teóricas e práticas, mostrando a Arte em seu aspecto prático e conceitual. Portanto, existe tanto no Canto Orfeônico, quanto na prática do professor entrevistado, a intenção em educar por meio da Música.

Quanto às apresentações, no Canto Orfeônico eram organizados grandes corais unificados pela mesma forma de ensino e conteúdo. Na escola visitada, acontecem apresentações pontuais dos resultados obtidos através de mostras de encerramento de bimestre para os demais integrantes do corpo docente e discente, sendo estas apresentações pontos em comum entre as práticas.

Por fim, durante a entrevista o professor ressaltou a importância da voz como um instrumento acessível a todos, e assim um meio vantajoso para o processo de democratização do ensino de Música. Na mesma direção, Villa-Lobos evidencia a voz cantada como o melhor instrumento para a democratização e acesso ao ensino de Música, pois é um instrumento acessível e, por isso, a prática do Canto Orfeônico nas escolas impunha-se como uma solução lógica, sendo esta mais uma semelhança entre tais práticas (LISBOA, 2015).

\section{CONSIDERAÇÕES FINAIS}

Após entrar em contato com diversas metodologias de ensino de Música, realizar uma visita ao contexto escolar e uma entrevista com um professor da área, passamos a fazer entrelaçamentos das teorias com a prática docente observada.

MACEDO, Eloilma Moura Siqueira; PARENTE, Filipe Ximenes Parente. O canto orfeônico e sua influência na prática docente. Revista da FUNDARTE. Montenegro, p.01-15, ano 21, no 45, junho de 2021.

Disponível em: http://.seer.fundarte.rs.gov.br/index.php/revistadafundarte/index> 30 de junho de 2021. 


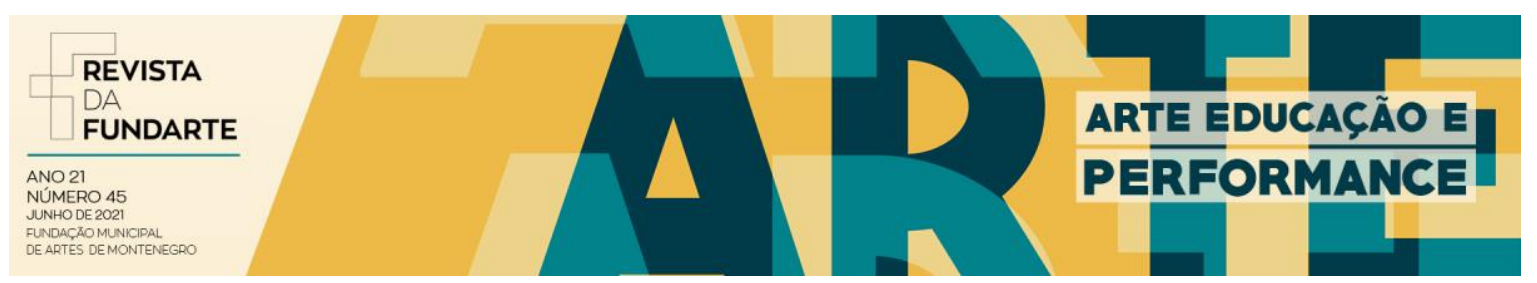

A influência detectada na ação docente do professor entrevistado é o Canto Orfeônico sistematizado por Heitor Villa-Lobos durante os anos 1930. Villa-Lobos fez dessa pedagogia uma de suas principais bandeiras. O orfeonismo consiste em possibilitar por intermédio do ensino de Música na escola a ritualização de símbolos nacionais brasileiros com o objetivo de criar uma comunidade sensível e que valoriza os ideais patrióticos por meio de repertório folclórico nacional e com o uso do canto coletivo, pois a voz cantada era o melhor instrumento para a popularização e acesso ao ensino de Música.

Sendo assim, concluímos que a atuação do Canto Orfeônico pode ser observada na prática docente do professor entrevistado, por meio do uso da voz como instrumento musicalizador e facilitador da Educação Musical, pois a mesma é um instrumento democrático e de fácil acesso à maioria das pessoas, e por meio das apresentações dos resultados dos ensaios de canto coletivo, do uso de repertório nacional e da valorização de músicas do contexto dos alunos.

Compreendemos que o olhar reflexivo sobre a prática docente é necessário, pois olhando para o passado podemos compreender a nossa práxis atual e, refletindo sobre a mesma, somos capazes mudá-la para o futuro. Assim, esta pesquisa pode fomentar numerosas inquietações no âmbito da escola básica, com seus respectivos professores, a fim de constatar as influências de outras metodologias em suas práticas docentes e refletir sobre as mesmas, visto que tal pensamento crítico é um impulso para a pesquisa-ação.

\section{Referências:}

CIAVATTA, L. O Passo: música e educação. Rio de Janeiro. Edição do autor, 2012.

CRUVINEL, Flávia Maria. O ensino coletivo de instrumentos musicais. Educação Musical e Transformação social. Goiânia: Instituto Centro-Brasileiro de Cultura. 6786, 2005.

DALCROZE, Émile Jaques. Methode Jaques-Dalcroze. Rhythmisch Gymnastik. Paris, Neuchatel, Leipzig: [s.n.], 1906.

MACEDO, Eloilma Moura Siqueira; PARENTE, Filipe Ximenes Parente. O canto orfeônico e sua influência na prática docente. Revista da FUNDARTE. Montenegro, p.01-15, ano 21, no 45, junho de 2021.

Disponível em: http://.seer.fundarte.rs.gov.br/index.php/revistadafundarte/index> 30 de junho de 2021. 


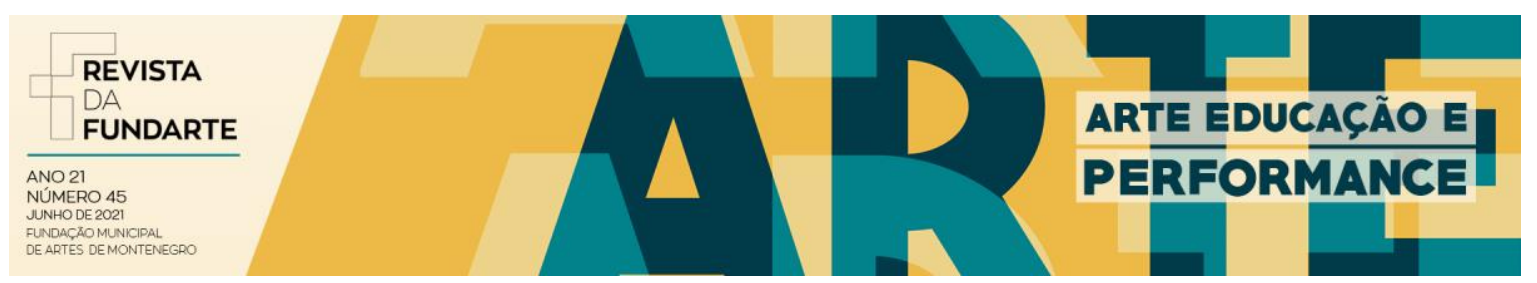

DEWEY, John. Democracia e educação: introdução à filosofia da educação. 3a. ed. São Paulo: Nacional. Tradução de Godofredo Rangel e Anísio Teixeira, 1959.

FREIRE, Paulo. Pedagogia da Autonomia: saberes necessários à prática educativa. $56^{\circ}$ ed. São Paulo: Paz e Terra, 2018.

GRAMANI, José Eduardo. Rítmica viva: a consciência musical do ritmo. Campinas: Editora da Unicamp, 1996.

GERHARDT, Tatiana Engel. SILVEIRA, Denise Tolfo. Métodos de pesquisa. Universidade Aberta do Brasil - Orgs: UAB/UFRGS, SEAD/UFRGS. Porto Alegre: Editora da UFRGS, 2009.120 p.

KOELLREUTTER, H. J. Harmonia funcional. São Paulo: Ricordi, 1986.

LISBOA, Alessandra C. Villa-Lobos e o Canto Orfeônico: música, nacionalismo e ideal civilizador. 2005. 183 f. Dissertação (Mestrado em Música) - Instituto de Artes da Universidade Estadual Paulista, São Paulo, 2005.

LOUREIRO, Alícia Maria Almeida. O ENSINO DA MÚSICA NA ESCOLA FUNDAMENTAL: UM ESTUDO EXPLORATÓRIO. Belo Horizonte, Mestrado em Educação da PUC/Minas, 2001.

MINAYO, M. C. de L. (Org.). Pesquisa social: teoria, método e criatividade. 19. Petrópolis: Vozes, 2009.

MIRANDA, Elvira Glória Drummond. Vivência Musical Vol. I. Fortaleza, Ceará -1998.

SÁ PEREIRA, Antônio. Ensino Moderno de Piano: Aprendizagem Racionalizada. 3a ed. São Paulo: Ricordi, 1964.

SOUZA, Carla Delgado de. O Brasil em pauta: Heitor Villa-Lobos e o canto orfeônico (1920-1945). Revista de Antropologia Social dos Alunos do PPGAS-UFSCar, v.4, n.1, jan.jun., p.67-85, 2012

VILLA-LOBOS, Heitor. O ensino popular da música no Brasil. Rio de Janeiro: Oficina Gráfica da Secretaria Geral de Educação e Cultura/Departamento de Educação do Distrito Federal, 1937.

MACEDO, Eloilma Moura Siqueira; PARENTE, Filipe Ximenes Parente. O canto orfeônico e sua influência na prática docente. Revista da FUNDARTE. Montenegro, p.01-15, ano 21, ํㅡ 45, junho de 2021.

Disponível em: http://.seer.fundarte.rs.gov.br/index.php/revistadafundarte/index> 30 de junho de 2021. 